\title{
O ENSINO DE HISTÓRIA NO BRASIL NA TRANSIÇÃO DA QUARTA PARA QUINTA SÉRIE: TENSÕES E PERSPECTIVAS
}

\section{TEACHING HISTORY IN BRAZIL IN TRANSITION FOR THE FOURTH FIFTH SERIES: TENSIONS AND PROSPECTS}

\author{
Lidiane Camila Lourençato ${ }^{1}$ \\ Marlene Cainelli ${ }^{2}$ \\ Talyta da Silva Selari
}

\begin{abstract}
RESUMO: Este artigo tem por objetivo apresentar algumas analises a partir das experiências proporcionadas por uma pesquisa de campo realizada em uma escola do ensino fundamental a partir dos preceitos da Educação Histórica. Pretende-se discutir, problemáticas inerentes ao ambiente escolar da quinta série ( $6^{\circ}$ ano) de uma escola pública. Buscamos perceber a partir de observações da aula de História, como os alunos e o professor exteriorizam os principais desafios e dificuldades da transição da quarta série ( $5^{\circ}$ ano) para a quinta série ( $6^{\circ}$ ano) do ensino fundamental.
\end{abstract}

Palavras chave: Educação Histórica. Ensino de História. Conhecimento histórico.

\begin{abstract}
This article present some analysis from the experiences provided by a field research conducted in a school of elementary education from the precepts of historical education. It is intended to discuss problems inherent in the school environment in the fifth grade ( 6 years) of a public school. We seek to understand the observations from the history lesson, as students and teacher externalize the main challenges and difficulties of the transition from fourth grade (5th years) middle school (6th year).
\end{abstract}

Keywords: Historical Education. Teaching history. Historical knowledge.

${ }^{1}$ Doutoranda em Educação pela UFPR.

2 Doutora em História Social. Professora de Metodologia e Prática do Ensino de História. Professora do Mestrado em História e do Mestrado em Educação da Universidade Estadual de Londrina.

${ }^{3}$ Graduada em História Pela UEL. 


\section{Introdução}

Este trabalho é fruto de uma pesquisa ${ }^{4}$, que tem por objetivo analisar as relações que constituem os sujeitos na passagem da quarta série ( $5^{\circ}$ ano) para a quinta série ( $6^{\circ}$ ano) do ensino fundamental. Chegamos a este objeto de estudo através de uma pesquisa empírica, realizada durante o ano de 2008 , com crianças da $4^{\circ}$ série do ensino fundamental de uma escola Municipal localizada no município de Londrina- PR. Nesta pesquisa objetivamos estudar acerca da possibilidade de alunos das séries iniciais aprenderem história, pois alguns estudos indicavam que crianças que não se encontravam no chamado período das operações formais ${ }^{5}$, não tinham capacidade para aprender conteúdos históricos. Isto era afirmado, pautado na ideia que crianças não conseguiriam entender o tempo, passado e futuro por serem conceitos abstratos, o que dificultaria o entendimento das seqüências, durações e simultaneidade dos acontecimentos e, também, das localizações espaciais destes acontecimentos.

Nessa hipótese de trabalho contradizia este tipo de afirmação. Tinhamos como pressuposto que crianças são capazes de elaborar relações sobre o conhecimento histórico tendo suas experiências como meio de organização temporal ancorando os novos conhecimentos a partir daqueles já existentes advindos da família e do meio social.

Os caminhos da investigação foram traçados a partir da Educação Histórica, principalmente em autores como Lee (2001) Barca (2004) e Schmidt (2009) para entendermos como crianças nas séries iniciais entendem os conceitos históricos e como percebem e entendem o tempo. Através desta pesquisa pudemos perceber que na prática da sala de aula muitas vezes a História ensinada nas séries iniciais tem o conhecimento

\footnotetext{
${ }^{4}$ Projeto de pesquisa "Educação Histórica: um estudo sobre a aprendizagem da história no processo de transição para a quinta série (60 ano) do ensino fundamental", este projeto tem financiamento do Cnpq e da Fundação Araucária.

5 Estes estudos são fruto da apropriação do pensamento de Jean Piaget para o ensino de história na educação básica.
} 
ligado aos fatos importantes da nação, especificamente das datas comemorativas.

\section{Observando a sala de aula}

No âmbito da pesquisa em Ensino de História, tem se destacado este campo denominado de Educação Histórica. Uma das suas preocupações que este grupo investiga está relacionada com a busca de elementos para a compreensão da consciência histórica, em especial de crianças e jovens por conta do campo de investigação centrado na educação formal e informal. Desta maneira, diversos estudiosos têm como objetivo investigar em suas pesquisas, como os conceitos históricos são compreendidos pelos alunos em tempos e espaços determinados, em diferentes sociedades.

A perspectiva de pesquisa da Educação Histórica está centrada na ideia da História como uma ciência que não se limita a considerar a existência de uma só explicação ou narrativa sobre o passado, mas que possui diversas perspectivas, entendendo que há uma objetividade na produção do conhecimento histórico. Desta forma, a história precisa ser conhecida e interpretada, tendo como base as evidências do passado e o desenvolvimento da ciência e de suas técnicas. Neste sentido, a educação histórica entende que há uma utilidade e um sentido social no conhecimento histórico, como por exemplo, para a formação da consciência histórica.

Segundo Garcia (2009), os avaliadores de pesquisas educacionais têm apontado que ainda existe um distanciamento entre as atividades de produção de conhecimento e o ensino no cotidiano escolar. As pesquisas na área de Educação Histórica têm contribuído para minimizar este problema, já que a investigação geralmente acontece no ambiente escolar tendo professores e alunos como elementos principais de analise. Isto ocorre nesta pesquisa, uma vez que temos como objetivo pesquisar professores e alunos dentro de escolas. Os dados são coletados através de observações das aulas de história e através de narrativas elaboradas pelos sujeitos no 
espaço escolar provocados por questionários e entrevistas elaborados pelo grupo de pesquisa.

A partir do término da pesquisa com crianças de $4^{a}$ série passamos a indagar como se daria a inserção destas crianças na $5^{a}$ série ( $6^{\circ}$ ano), pois os alunos se deparam com uma aprendizagem dividida em disciplinas, com professores especialistas, como então os saberes escolares aprendidos nas séries iniciais dialogariam com os aprendidos no ensino fundamental?

$\mathrm{Na}$ passagem da quarta para a quinta série acreditamos que os professores deveriam evidenciar práticas que permitissem 0 desenvolvimento de recursos pessoais dos alunos, até então, não acionados e que as aprendizagens do passado deveriam dialogar com as novas aprendizagens. Esta passagem é vista como um momento de dificuldades, pois os espaços e o ritmo de estudo são diferentes. Esta fase é descrita como uma época de transformações e desafios, especialmente para o aluno.

No primeiro ano de realização desta pesquisa (2009) optamos como procedimentos de investigação a aplicação de um questionário aos alunos da $5^{a}$ série de uma escola estadual na cidade de Londrina, a qual a maioria dos alunos acompanhados pelo projeto na quarta série decidiu continuar os estudos. O objetivo do instrumento de pesquisa foi investigar quais relações os alunos estabeleceriam entre a quarta e quinta série, assim como perceber as diferenças e semelhanças da relação professor-aluno destas séries.

Outro procedimento utilizado foi a observação das aulas de história, onde procurávamos mapear o comportamento dos alunos entre si, com o professor de história e a relação destes sujeitos com o conhecimento histórico apresentado pelo professor.

Já no segundo ano (2010), optamos como metodologia a observação de alunos de duas quinta séries da mesma escola e que tinham o mesmo professor de história da sala observada no ano anterior. A aplicação de um questionário para os alunos e outro para o professor também foi realizada.

As salas observadas no segundo ano de pesquisa eram a $5^{a}$ série $\mathrm{A}$ e $5^{\text {a }}$ série $B$. Logo no primeiro dia de observação notamos que estas salas 
eram bastante diferentes das observadas no ano anterior (2009) na quarta série, sendo que nesta primeira sala percebemos que os alunos eram indisciplinados no sentido de falar bastante e alto, andar pela sala durante a aula toda, gritar e não respeitar o professor na hora em que ele pedia silêncio para falar. Também pudemos observar em vários momentos comportamentos agressivos entre os alunos, sendo estes tanto verbais como físicos.

Hauser em uma dissertação cujo objetivo foi apresentar o estado da arte de pesquisas sobre a transição escolar da quarta para a quinta série indica que a indisciplina é o problema mais destacado nas pesquisas sobre o assunto. Segundo a autora, apoiando-se nas falas de professores a partir de diferentes pesquisas:

Para estes (os professores), os alunos vindos da $4^{a}$ série
sentem-se muito livres e soltos na $5^{a}$ série, o que os faz mais
indisciplinados. Por não terem mais a vigilância de uma única
professora como acontecia na $4^{a}$ série, muitos alunos
comportam-se como se não tivessem limites. Na verdade,
desconhecem as regras escolares dessa nova escola e
percebem cedo a heterogeneidade didática e pessoal entre
seus novos professores. Assim, vão descobrindo que há
professores que lhes dão maior ou menor liberdade em sala de
aula e com os quais se relacionam melhor ou pior (HAUSER,
2007, p. 47).

Já as salas observadas no último ano (2010) eram mais concentradas nas atividades, os alunos pareciam serem mais novos e quando o professor chamava a atenção, na maioria das vezes ele era atendido. Também notamos que apenas nos momentos em que os alunos dizem um palavrão para os colegas, o professor se sentia responsável pelo comportamento de seus alunos e intervia pedindo para que eles se desculpassem.

Dias da Silva (1997, p.123) destaca que o professor da quinta série entende que ocupar seu tempo com questões não relacionadas aos saberes referentes à sua matéria é "um desvio de função". E ainda, a "boa aula" tem a matéria como centro. Do aluno, espera-se uma postura disciplinada para "pensar, se organizar e participar". O silêncio, por várias vezes é entendido como condição primeira para a aprendizagem em sala de aula. 
O grande incômodo que a $5^{a}$ série causa aos professores, segundo Dias da Silva (1997) relaciona-se ao fato de que, nessa sala, as contradições profissionais são explicitadas:

As $5^{a}$ séries parecem sínteses dos dilemas cotidianos de seus professores, que envolvem algo muito mais enraizado que a alteração de procedimentos didáticos isolados. Dilemas porque implicariam também a alteração de seu saber sobre seu trabalho, a própria concepção de seu papel e de sua função na escola. (DIAS DA SILVA, 1997, p. 124)

Refletindo sobre a organização das aulas do professor, encontramos inúmeras estruturações, mecanismos didáticos e de controle em sua metodologia, também observamos os posicionamentos com relação aos alunos e ao conteúdo com o qual ele trabalha. Entretanto, alguns destes procedimentos são mais recorrentes e podemos discuti-los teoricamente, na medida em que já identificados em outros ambientes e se apresentam como práticas menos restritas em comparação às outras, que aparecem mais ligadas as particularidades da organização daquela sala em si. Para este trabalho optamos por analisar a relação do professor com a utilização do livro didático de história e como este se insere no contexto da aula da $5^{a}$ série $A$ e $5^{a}$ série $B\left(6^{\circ}\right.$ ano). O livro utilizado pela turma é Projeto Araribá história 6 ( $5^{\mathrm{a}}$ série $\left.6^{\circ} \mathrm{ano}\right)^{6}$.

\section{O uso do livro didático}

Dentro da composição das aulas as crianças manipulam bem o livro e este aparece como suporte textual. Nas observações notamos que o professor poucas vezes escreve textos na lousa para que as crianças copiem ou traz textos para sala de aula e geralmente utiliza os textos organizados no livro, seguindo a organização cronológica deste no estudo das sociedades.

${ }^{6}$ Editora Moderna, coleção Projeto Araribá História \& Ensino, Londrina, v. 18, n. 2, p. 143-160, jul./dez. 2012 
É em torno das informações organizadas neste livro, que o professor estrutura a aula, pois depois da leitura que eles realizam de forma individual e silenciosa - não chegamos a presenciar momentos de leitura compartilhada ou em voz alta - o professor explica organizando as informações do livro na lousa. Essa atividade é bem ampla envolvendo a sala toda. O professor coloca o título dos tópicos do livro que ele quer que os alunos copiem e vai perguntando as características do conteúdo que os alunos leram, compondo com essas respostas os tópicos que eles terão anotados em seu caderno e assim discutindo e acrescentando novas informações ou reformulando as colocações dos alunos, que ele considera que tiveram uma compreensão parcial ou diferente do sentido que o livro expressa.

Nesse sentido podemos relacionar com que nos diz Bittencourt

O livro didático é também um depositário de conteúdos escolares, suporte básico e sistematizador privilegiado dos conteúdos elencados pelas propostas curriculares; é por seu intermédio que são passados os conhecimentos e técnicas considerados fundamentais de uma sociedade em determinada época. (BITTENCOURT, 1998, p.72)

Para Rüsen (2010) diante da importância já comprovada por especialistas da utilização do livro no processo de ensino aprendizagem é possível se pensar em um livro didático de história ideal. $\mathrm{O}$ autor afirma que um livro didático

Deve oferecer explicações inteligíveis e verificáveis, sem se limitar, entretanto, a meras informações de fatos, bem como evitar por princípio argumentações monocausais e insistir no fato de que a interpretação histórica está aberta por princípio às argumentações multicausais. Assim, deve apresentar o conhecimento histórico de forma argumentativa, e evitar qualquer aparência de uma certeza dogmática. (RÜSEN, 2010 p. 123)

Neste processo, podemos perceber que o professor faz do livro a figura central do processo de ensino aprendizagem da história na sala de 
aula, as discussões e os conteúdos que os alunos anotarão partem do conhecimento e das características discutidas pelo livro didático. A partir dele se estrutura a aula e a organização da discussão dos conhecimentos históricos a cerca das sociedades estudadas.

É compreensível que o professor se sinta seguro ao utilizar um livro didático que ele supostamente avaliou e escolheu ${ }^{7}$ considerando-o como suporte suficiente para sua aula. Entretanto, entendemos que é possível e necessário problematizar a figura do livro, à medida que este ocupa dentro do ambiente escolar o papel de detentor do conhecimento, das informações e da verdade. É a partir dele que o professor fala, depois dele é que o professor se posiciona, para garantir que o que eles leram seja bem sistematizado de acordo com a organização construída na lousa durante a discussão com seus alunos.

Esta utilização do livro como detentor do conhecimento não se restringe ao momento de exploração e discussão dos conteúdos. O professor também pauta no livro muitas das atividades desenvolvidas durante a aula, estas quando não são propostas pelo livro didático, são com consulta no material didático e nas anotações do caderno. Ou seja, o livro não só transmite o que eles precisam saber para discutir com o professor, mas também retoma e delimita as informações que eles devem reter. Até quando o professor traz uma atividade impressa de casa, esta dialoga com os textos informativos do livro didático e com seu vocabulário.

Para exemplificar essa relação entre o conteúdo do livro e as atividades, podemos retomar uma das situações ocorrida durante o período que estivemos observando as aulas de História. O capítulo sobre a religiosidade egípcia trazia uma palavra que se agregaria ao vocabulário dos alunos e com a qual eles estabeleceram uma grande interação e estranhamento. O vocábulo em questão é o conceito utilizado para caracterizar os Deuses Egípcios e os denomina Antropozoomórficos.

\footnotetext{
${ }^{7}$ Consideramos que o professor supostamente escolheu o livro didático que utiliza devido ao Programa Nacional do Livro Didático (PNLD), onde os professores das disciplinas têm a oportunidade de analisar e escolher os livros que usarão através do guia do livro didático.
} 
Ao lerem essa palavra no texto do livro didático, os alunos logo demonstraram um espanto e começaram a perguntar ao professor, o que significava. O professor explicou a epistemologia da palavra e a sua relação com os significados religiosos que os egípcios encontravam na natureza e em alguns animais, e como os historiadores usaram essa palavra para designar a característica e o significado daqueles Deuses. Depois da explicação, os alunos ainda se divertiram tentando encaixar a palavra em outras frases e contando as sílabas e letras que eles acharam exageradamente grande e diferente.

Dias depois numa atividade que o professor formulou, estava presente o termo antropozoomórfico, e o exercício relacionava a palavra com o seu significado e as características da religiosidade egípcia, exatamente como o livro e a discussão deles havia relacionado nas aulas anteriores. Podemos entender que o livro: Nesse processo ele cria padrões lingüísticos e formas de comunicação específicas ao elaborar textos com vocabulário próprio, ordenando capítulos e conceitos, selecionando ilustrações, fazendo resumos etc. (BITTENCOURT, 1998, p.72)

A discussão do termo antropozoomórfico entre as atividades, os alunos e as abordagens feitas pelo professor, de forma geral teriam possibilitado que informações novas e conceitos diferentes fossem agregados ao conhecimento histórico dos alunos, compondo assim sua compreensão da história, ou seja, discutindo esses termos representativos e deixando que os alunos tenham com eles relações de estranhamento e reflexão, o professor possibilitaria a construção do conhecimento histórico acerca de determinado aspecto sobre a sociedade discutida.

Tendo que lidar com o que o termo representa e que informações ele possibilita sobre a vida de outras sociedades, o aluno lida com a adição de novos significados ao seu olhar, sobre os conteúdos trabalhados com o professor. Aqui levamos em consideração que esses alunos podem trazer já pré-concepções de determinados vocábulos que os historiadores e mesmo os livros didáticos de história usam com propriedade como se fossem peças que se encaixam e formam o texto. Mas, nem sempre ao construir esses 
textos demonstram que estas palavras ou vocábulos podem ser utilizados em outros contextos escolares ou não.

Nesse caso a figura do professor é muito importante e pode fazer a diferença em uma aprendizagem significativa a partir do momento que aparece explorando a palavra com os alunos, possibilitando que eles investiguem como se formou e quais os significados dessa palavra "enorme e diferente", que é formada por palavras que eles já conhecem e palavras novas, numa junção que pretende facilitar e comunicar características essenciais para compreensão do quão plural pode ser uma religião ou sociedade diferente da nossa.

Esse processo complexo envolve relacionar os conceitos e palavras bem como seus significados, abandonando algumas compreensões e somando novas que se aplicam a abordagem histórica, mas não necessariamente a todas as utilizações possíveis desses termos em outras situações.

Mas a respeito da utilização de determinadas palavras nos textos do livro didático, Rüsen afirma que o livro didático deve considerar as condições de aprendizagem dos alunos e alunas ao dizer que "tem que estar de acordo com a sua capacidade de compreensão, e isto vale, acima de tudo, no que se refere ao nível de linguagem utilizado" (2010, p. 116).

Abordando esse processo Zamboni (1998) afirma que "Com relação à produção do conhecimento em sala de aula, lidamos diretamente com a construção e elaboração de imagens e palavras". Construir esse novo significado ou agregar significados históricos às palavras já existentes no vocabulário dos alunos, não só depende crucialmente do professor e do ambiente de sala de aula, como nos possibilita ver como se dá a construção constante do conhecimento nesse ambiente escolar, construção que acontece a cada novo debate.

Nesse momento de discussão e de reflexão em que o professor e os alunos vão compondo a construção dos conceitos, o livro didático poderia deixar de ser a figura estrutural da aula, apesar da discussão ter partido dos recursos textuais do material didático. Isto ocorreria como se fosse um 
movimento, onde as atenções se desprendem do livro e passam aos sujeitos envolvidos no processo de ensino aprendizagem.

Nestes componentes não textuais, o professor e os alunos deslocam a discussão do livro e da lousa para o espaço do diálogo, onde o aluno ousa expor em voz alta para os colegas o impulso de sua interpretação, o significado que o vocábulo lhe remeteu e que já trazia consigo.

Quando um aluno estabelece uma relação entre a matéria estudada e outro assunto todos os colegas participam da discussão acerca da aceitação ou não daquele significado, como na aula observada onde um aluno relacionou o termo "aos Deuses antropomórficos sugerindo que significavam algo parecido aos antropozoomorficos" e o professor diferencia os dois termos a medida que os alunos continuam expondo suas interpretações, contrapondo entre si e com o professor. Neste movimento o grupo decide a partir das orientações do professor de história como esse novo conceito, que somava diversas palavras que eles conheciam iria ser incorporado ao seu vocabulário relacionado à história, tentando com suas ideias e sempre atentos ao que o professor dizia chegar aos significados que antropozoomórfico carregava acerca da sociedade estudada.

Também sobre o uso do livro didático temos que lembrar que sua utilização deveria ser feita apenas como um suporte textual durante as aulas, tendo em vista que este representa a história como uma verdade absoluta, impedindo qualquer tipo de argumento capaz de colocar em dúvida as discussões realizadas e acreditamos ser de grande importância mostrar para as crianças que existem diferentes experiências históricas, portando há diferentes possibilidades de interpretação sobre um mesmo acontecimento. Rüsen (2010) afirma que

Tem que abrir os olhos das crianças e jovens às diferenças históricas e às diferentes qualidades da vida humana através dos tempos. Portanto, não devem apresentar unicamente as experiências históricas já interpretadas e as percepções já assimiladas de forma cognitiva. (RUSEN, 2010, p. 119) 
Deslocando nosso olhar da figura e o lugar de centralidade que o livro didático ocupa no processo de ensino aprendizagem da história passaremos a discussão do uso de componentes não textuais para a abordagem da História e como percebemos isto no caso das aulas que abrangeram nosso debate.

\title{
Componentes não textuais
}

Dentro desses aspectos nossa pesquisa possibilitou perceber as dificuldades do professor de trabalhar o conteúdo de História Antiga na $5^{a}$ série ( $6^{\circ}$ ano). Seja pela ideia de distancia temporal ou pela questão espacial, este conteúdo acaba por demandar estratégias por parte do professor para conseguir atenção dos alunos.

Sobre as praticas escolares no ensino de história antiga, Silva (2010) afirma:

\begin{abstract}
Sobre esta falta de conexão com a realidade do aluno cumpre ressaltar que não acreditamos que os livros e aulas devam incentivar o aluno a uma busca pelas origens do que existe na atualidade, fazer isso seria, além de perigoso, desconsiderar as mudanças e transformações históricas. Devemos buscar compreender o passado por ele mesmo e o presente como resultado de transformações. (SILVA, 2010, p 149)
\end{abstract}

Com relação a esse exercício de postura frente ao passado, o que tivemos oportunidade de observar nas aulas que presenciamos, segue de certa forma essa ideia de que o presente não teve todas suas praticas originadas no passado, que muitas diferem e que não são conseqüências do passado.

Entretanto essa pratica se torna um pouco mais árdua quando se trata da $5^{a}$ série, pois os alunos até a $4^{a}$ série têm seus estudos de história mais focados na história local e nacional, muitas vezes imerso no cotidiano das problemáticas presentes. Sendo assim quase constantemente os alunos tentam comparar características do passado que o professor aborda aos aspectos sociais do dia-a-dia e as figuras locais da política e da mídia. 
Vemos então o professor da quinta série numa pratica constante, de ouvir a comparação que os alunos realizam entre os tempos. Perceber as relações que estes estabelecem com o conteúdo, como diferenciam as situações atuais das ocorridas no passado, além de entender os significados que essas situações apresentam nos diferentes contextos, possibilitando que o aluno perceba um distanciamento entre as duas realidades, a estudada no contexto do Egito antigo e a do Egito atual bem como da comunidade em que o aluno vive.

Uma das estratégias utilizadas nas aulas que observamos foi o uso mais sistemático de mapas geográficos e a utilização de documentários. Dentro da temática do Egito Antigo, o professor trouxe para sala de aula um vídeo de alguns minutos, que mostrava e narrava algumas histórias do Egito, sua religiosidade, as pirâmides e os Faraós.

Apesar de ser um pouco longo o vídeo prendeu a atenção de boa parte da sala, e mesmo sendo antes do fim do período de aulas do dia os alunos não estavam agitados e conseguiram se concentrar. 0 vídeo tinha 0 papel de complemento do que o professor havia explicado durante a aula, pois apesar de quase repetir o conteúdo que ele havia ministrado, trazia, entretanto, imagens captadas e produzidas em alta tecnologia além do tom do narrador que garantia uma grandiosidade ao conteúdo.

Apesar das imagens parecerem um recurso ótimo para abordagens da história, nesse caso coube a este material o posto de apêndice. Ao colocar o vídeo no fim da aula o material se caracterizou como uma forma mais leve de ver aquele conteúdo, apenas a critério de diversificação, e sem espaço para discussão. Em nosso entendimento o debate sobre o assunto era fundamental, partindo do pressuposto que o aluno relacionaria a aula ao vídeo tomando para si interpretações e novas questões. A falta do espaço para discussão depois do vídeo impossibilitou o professor de desfazer possíveis interpretações errôneas e anacronismos, bem como sanar o surgimento de novas dúvidas.

O uso do vídeo em sala de aula contribuiu enfim para cristalizar em imagens aquilo que o professor havia trabalhado em sala de aula com o 
agravante de ao preencher o tempo da aula com imagens que representam o passado investigado como um documento histórico o professor usa a fonte como meio de sustentar seu discurso, no sentido de dar concretude e realidade sobre sua fala. Inserir o vídeo em sala de aula como um documento

Pode se tornar um modo de submeter a epistemologia da história à didática, na medida em que o documento passa a ser o objeto concreto que vai dar veracidade ao relato histórico. A submissão da epistemologia da história à didática é decorrência da noção essencialista de que as crianças e os adolescentes em qualquer situação, precisam ter o concreto diante de si para aprender o conceito. (PEREIRA; SEFFNER, 2008, p.125)

Esta relação com o conhecimento histórico fez com que o professor não estabelecesse com os alunos após o vídeo um momento didático de discussão. A sua fala e o vídeo já representavam aquilo que o professor entendia como necessário sobre o conteúdo trabalho. Um complementava o outro na intenção de transmitir a matéria.

A sala de aula é um lugar onde na figura do professor e dos alunos figuram espaços diversos de relacionamentos e sentidos, sobre identidade, autoridade, afetividade. Nesse sentido percebemos nas observações realizadas nestes dois anos que o professor da quinta série, de certa forma, não assume responsabilidade pela formação do aluno como um indivíduo. Ele se sente apenas responsável pela aprendizagem dos conteúdos da disciplina a qual ministra. Mesmo que o professor se ausente de um interesse maior pelas questões que não dizem respeito direto a matéria que leciona, "entendemos que nem o aluno, nem o professor são os mesmos depois do diálogo. O processo de ensinar e aprender, visto como unidade, parece, de fato, constituir um desafio à permanência da mesmice." (TUNES, TACCA e BARTHOLO JÚNIOR, 2005, p.693)

Pudemos observar inúmeras vezes, o professor chamar a atenção dos alunos dizendo que problemas de indisciplina, mesmo na sala de aula, brigas e discussões eram para ser resolvidas na direção da escola, pois a sala de aula era para estudar o conteúdo da disciplina de história. Outro 
exemplo deste sentimento de fragmentação na responsabilidade pelos alunos ocorreu nos momentos em que o professor alertava-os a respeito das suas dificuldades e erros apresentados principalmente em provas.

Ao fazer a correção de uma prova aplicada aos alunos, o professor alerta que muitos erraram uma questão que exigia o conhecimento dos numerais romanos. O professor fala então às crianças que muitos estão com dificuldades neste assunto e que este conteúdo é responsabilidade da quarta série e que eles já deveriam saber. Ao invés de tentar ajudar os alunos que estão com dificuldade, ele manda que eles peguem a apostila da quarta série e revisem, justificando que quando não aprendemos no tempo certo, depois temos que correr atrás dos prejuízos sozinhos.

Outro momento em que percebemos esta atitude de não responsabilidade além do conteúdo da disciplina foi mais uma vez durante uma correção de prova, onde o professor alerta os alunos a respeito dos erros gramaticais. Ele diz que os textos produzidos pelos alunos não tem coerência, que escrevem frases pela metade e que estas ficam soltas, que não escrevem os nomes próprios com letra maiúscula, trocam letras, não acentuam as palavras entre outros erros. Afirmando que os alunos devem procurar corrigir estes erros e que isso demonstra falta de leitura. Também afirma que os professores de língua portuguesa não darão conta de corrigir e apontar erro por erro, ainda mais que a carga horária de português está baixa. Ele coloca que a situação esta muito grave e parece muito nervoso com isto.

Termina sua indignação contando aos alunos que tem casos no terceiro ano do ensino médio de alunos que não sabem escrever, deixandoos bastante assustados, e afirma "que o diploma não garante nada e se não souberem pelo menos escrever direito não conseguirão emprego". 


\section{Considerações finais}

Podemos perceber com estes exemplos e com outras situações presenciadas na sala de aula, que o professor da $5^{a}$ série tem uma imagem dos alunos diferente de um professor de $4^{a}$ série. Em um curto tempo estas crianças passam a ser vistas como responsáveis pelos seus atos e pelas suas dificuldades, pois o professor deixa de se responsabilizar pelo aluno como um todo e passa a sentir apenas responsabilidade pelo conteúdo da ciência de referencia a ser transmitido. Também pudemos perceber a importância que é dada por um professor de $5^{a}$ série ao livro didático, uma vez que se torna norteador das aulas, e na maioria das vezes também delimitador, pois o professor acaba refém do seu conteúdo.

Nesse sentido entendemos que a relação entre professor, aluno e conhecimento acaba sendo prejudicada, que efetivamente não se constitui uma formação de pensamento tendo em vista o que afirmam TUNES, TACCA e BARTHOLO JÚNIOR,

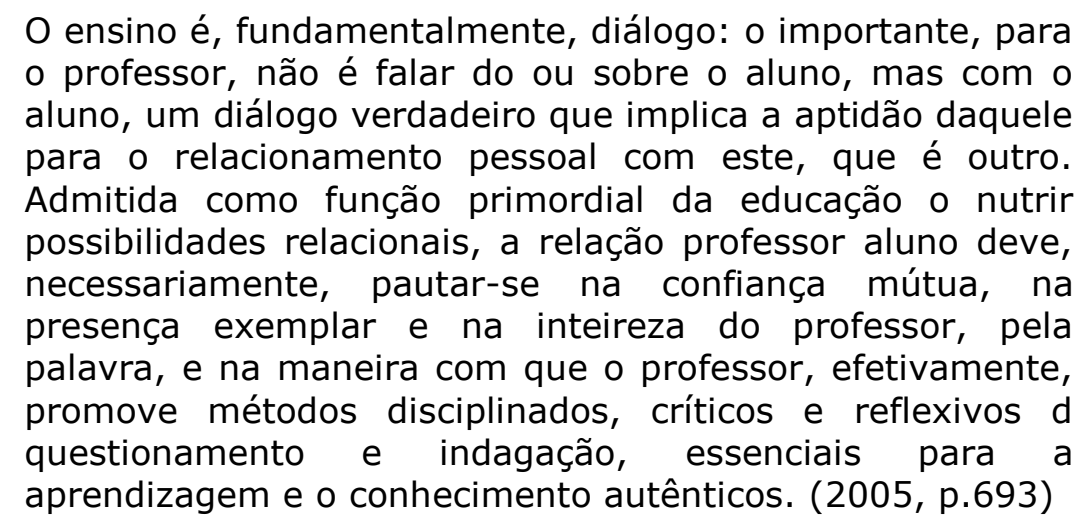

Através da observação das aulas de história, do mapeamento do comportamento dos alunos entre si, com o professor e a relação destes sujeitos com o conhecimento histórico apresentado, pudemos constatar que são pequenos fatos e posturas tomadas dentro de uma sala de aula que podem tornar a passagem da $4^{a}$ serie ( $5^{\circ}$ ano) para a $5^{a}$ serie ( $6^{\circ}$ ano) mais difícil, caracterizando este período como um momento de desafio para o 
aluno e que as aprendizagens do passado, ao invés de dialogarem com as novas aprendizagens, são apenas cobradas como uma obrigação destes.

A relação da aprendizagem da história no processo de transição da quarta para quinta série esteve no centro de nossa investigação nos últimos dois anos. Pesquisamos como o aluno se relaciona com o conhecimento histórico nas séries iniciais e depois na series finais do ensino fundamental tendo como hipótese principal uma diferença substancial na forma de ensinar história entre os níveis. Em nossa concepção a formação específica do profissional de história determinaria uma especificidade na forma de ensinar história para crianças e na mobilização de conhecimentos históricos em direção à ciência da história e consequentemente a formação do pensamento histórico.

Nas observações realizadas no campo de pesquisa o olhar do pesquisador se debruçou sobre as relações que estes profissionais apresentam sobre a história a ser ensinada e como estes operacionalizam esta tarefa no cotidiano escolar, nesse sentido percebemos que a investigação que envolve a participação do pesquisador no campo de pesquisa em observações sistemáticas significa para o pesquisador um árduo trabalho de concentração durante dias e semanas, no entanto, não entendemos um outro método de trabalho que não envolva a permanência deste em sala de aula.

\section{Referências Bibliográficas:}

BARCA, I. O pensamento histórico dos Jovens. Braga: Universidade do Minho, 2000.

BITTENCOURT, C. Livros didáticos entre textos e imagens. In:

BITTENCOURT, C. (Org.). O saber histórico em sala de aula. São Paulo: Contexto, 1998.

DIAS DA SILVA, M. H. G. F. Passagem sem ritos: Passagem sem ritos: as quintas séries e seus professores. Campinas: Papirus, 1997.

EDWARDS, V. Os sujeitos no universo da escola. Trad. Josely Vianna Baptista. São Paulo: Ática, 1997. 
GARCIA, T. M. F. B. Relações entre o ensino e aprendizagem histórica: desafios para a pesquisa em Educação Histórica. In: SCHMIDT, M. A. BARCA, I (Org.). Aprender História: perspectivas da educação histórica. Ijuí: Ed. Unijuí, 2009.

HAUSER, S. D. R. A transição da $4^{a}$ para a $5^{a}$ série do Ensino Fundamental: uma revisão bibliográfica (1987-2004). Dissertação de Mestrado em Psicologia da Educação no Stricto Sensu da Pontifícia Universidade Católica de São Paulo. PUC - SP, 2007.

PEREIRA, N. M.; SEFFNER, F. O que pode o ensino de história? Sobre o uso de fontes na sala de aula. Anos 90, Porto Alegre, v. 15, n. 28, p. 113-128, dez. 2008.

RUSEN, J. O Livro didático ideal. In. SCHIMDT. M. A.; BARCA, I.; MARTINS, Estevão de Rezende (Org.). Jörn Rüsen e o ensino de história. Curitiba:

Ed.UFPR, 2010.

SILVA, S. C. Aspectos do ensino de História Antiga no Brasil: algumas observações. Alétheia. Revista de estudos sobre Antiguidade e Medievo [on line]. V. 1, jan/jul de 2010. Disponível em

<http://revistaale.dominiotemporario.com/page_3.html> Acesso em $01 / 2011$.

TUNES, E.; TACCA, M. C. V. R.; BARTHOLO JÚNIOR, R. dos S. de. Cadernos de Pesquisa, v. 35, n. 126, set./dez. 2005

ZAMBONI, E. Representações e linguagens no ensino de história. Revista Brasileira de História. São Paulo, v. 18, n. 36, 1998. Disponível em: <http://www.scielo.br/scielo.php?script=sci_arttext\&pid=S0102$01881998000200005 \&$ lng =en\&nrm=iso > Acesso em 01/ 2010.

Recebido em 10 de Junho de 2012. Aprovado em 10 de Janeiro de 2013. 